\title{
Sperm development, age and sex chromosome meiotic drive in the stalk-eyed fly, Cyrtodiopsis whitei
}

\author{
GERALD S. WILKINSON* \& MARA I. SANCHEZ \\ Department of Biology, University of Maryland, College Park, MD 20742, U.S.A.
}

\begin{abstract}
The cytological basis of $\mathrm{X}$ chromosome meiotic drive or sex ratio (SR) has been reported for several species of Drosophila but not for other species. Here we describe how sperm development in the stalkeyed fly, Cyrtodiopsis whitei, influences progeny sex proportion, in order to determine if a common developmental mechanism could cause meiotic drive in these distantly related taxa. Because age has been found to affect the degree of segregation distortion in some Drosophila, we tested flies from six to 26 weeks of age. We find that spermatocyst bundles in SR males frequently contain incompletely elongated spermatid nuclei independently of male age. Older males have, however, more spermatocyst bundles in their testes than younger males. Abnormal spermatid elongation affects male fertility since SR males produce $74 \%$ as many progeny per week as ST males. The proportion of spermatocyst bundles with improperly elongated spermatid nuclei explains $71 \%$ of the variation in progeny sex proportion. After reviewing the literature on sperm development and meiotic drive, we conclude that the cytological basis of meiotic drive in diopsids closely resembles Drosophila. Across species in both groups, the production of fertile males is associated with less than half of all spermatids not elongating normally in a spermatocyst bundle. We discuss the possibility that frequency-dependent selection on male fertility could stabilize the drive polymorphism in these unusual flies.
\end{abstract}

Keywords: meiotic drive, sex-ratio, spermatogenesis.

\section{Introduction}

The term 'meiotic drive' is used to indicate when a gene or chromosomal region is consistently transmitted to more than half of an individual's progeny (Lyttle, 1993). Several well studied cases involve autosomal genes, i.e. the $t$-locus in house mice, Mus musculus (Silver, 1993), segregation distorter (SD) in Drosophila melanogaster (Merrill et al., 1999), and chromosomal knobs in maize, Zea mays (Buckler et al., 1999); however, more cases of sex chromosome meiotic drive have been reported (Hurst \& Pomiankowski, 1991). For example, over 20 species of Diptera are known to exhibit sex chromosome meiotic drive including Drosophila in the obscura (Gershenson, 1928; Sturtevant \& Dobzhansky, 1936), melanica (Stalker, 1961), tripunctata (Carvalho et al., 1989), testacea (James \& Jaenike, 1990), melanogaster (Mercot et al., 1995; Dermitizakis et al., 2000) and quinaria (Jaenike, 1996) groups, as well as tsetse flies, Glossina morsitans (Gooding, 1986), Aedes and Culex mosquitoes (Wood \& Newton, 1991), Sciara ocellaris

*Correspondence. E-mail: gw10@umail.umd.edu
(Mori et al., 1979), and at least two diopsid stalk-eyed flies, Cyrtodiopsis whitei and C. dalmanni (Presgraves et al., 1997). Because sex chromosome meiotic drive is difficult to detect without extensive captive breeding, some have suggested that undocumented cases may be common (Jaenike, 1996; Carvalho \& Vaz, 1999). In the absence of any opposing force, sex chromosome meiotic drive should cause population extinction when fixation occurs and only one sex remains (Hamilton, 1967).

Persistent polymorphisms for X chromosome meiotic drive, often referred to as sex ratio or SR, are, however, known for many species, with some also exhibiting Y-linked and autosomal suppression, e.g. Drosophila mediopunctata (Carvalho \& Klaczko, 1993, 1994), D. simulans (Cazemajor et al., 1997) and D. quinaria (Jaenike, 1999a). A stable sex ratio polymorphism can be maintained either by differential fitness of female genotypes (Edwards, 1961; Carvalho \& Vaz, 1999) or by frequency-dependent selection operating via male fertility (Jaenike, 1996). The latter scenario requires that SR males have less than half the fertility of ST males, as appears to be the case for D. recens (Jaenike, 1996). The presence of $\mathrm{Y}$ chromosome or autosomal suppressors 
tends to restore sex proportion towards $1: 1$ and, as a consequence, influences the magnitude of selection necessary to maintain a stable SR polymorphism ( $\mathrm{Wu}$, 1983; Carvalho et al., 1997; Jaenike, 1999a, b).

Meiotic drive typically operates by differential survival of sperm (Lyttle, 1993). For example, during spermatogenesis only half of the spermatids within a sperm bundle complete development and undergo individualization in male Drosophila melanogaster heterozygous for SD (Peacock et al., 1972). Similar abnormal sperm development has been reported for sex ratio male D. pseudoobscura (Policansky \& Ellison, 1970), D. subobscura (Hauschteck-Jungen \& Maurer, 1976), D. neotestacea (J. Jaenike, personal communication), and D. simulans (Montchamp-Moreau \& Joly, 1997). Recent studies on $D$. simulans SR males using in situ hybridization with fluorescent markers specific to each sex chromosome have revealed that spermatids which fail to elongate either carry a Y chromosome or lack any sex chromosome and therefore represent products of nondisjunction (Cazemajor et al., 2000). SR males are expected to produce fewer functional sperm than ST males and have reduced fertility as a consequence (Jaenike, 1996).

The primary aim of this study is to determine the developmental mechanism of sex chromosome meiotic drive in the stalk-eyed fly, Cyrtodiopsis whitei. Because most of our understanding of the cytological basis for meiotic drive comes from studies on Drosophila, detailed study of drive in diopsids should reveal if a common developmental mechanism causes meiotic drive in these distantly related flies. Furthermore, determining how meiotic drive affects sperm development may also reveal if frequency-dependent selection on male fertility provides a plausible mechanism for stabilizing an SR polymorphism in stalk-eyed flies.

Genetic analyses of Cyrtodiopsis dalmanni, the sister species to C. whitei (Wilkinson et al., 1998a), have demonstrated that an $\mathrm{X}$-linked factor causes males to produce predominantly female progeny, and that the magnitude of drive is influenced by both Y-linked and autosomal factors (Presgraves et al., 1997). C. whitei exhibits a similar distribution of progeny sex proportions (Wilkinson et al., 1998b) but has a higher frequency of SR in the wild. Both species exhibit dramatic sexual dimorphism for eye span and mating is concentrated at dusk and dawn in female-biased aggregations where large eye-span males often mate repeatedly over short periods of time (Lorch et al., 1993). Females of both species remate frequently and, on average, more often than a congener, $C$. quinqueguttata, which lacks drive and is sexually monomorphic for eye span (Wilkinson et al., 1998b). Females of the two dimorphic species, but not the monomorphic species, prefer to mate with males possessing long eye span (Wilkinson et al., 1998a), a trait that exhibits linkage to meiotic drive (Wilkinson et al., 1998b). Population genetic models (Lande \& Wilkinson, 1999) show that meiotic drive can catalyse sexual selection by female choice assuming that the drive polymorphism is otherwise maintained by selection.

Age represents a potential confounding factor in determining the mechanism underlying meiotic drive because other studies have reported that age influences drive expression. For example, in $D$. mediopunctata the degree of female bias, and hence the magnitude of meiotic drive for sex ratio, increases with male age (Carvalho \& Klaczko, 1992). In contrast, in D. melanogaster segregation distortion decreases with age because fewer SD sperm are produced by older males (Hiraizumi \& Watanabe, 1969). The differences in life history between stalk-eyed flies and most Drosophila make it difficult to predict how age might influence sperm production and meiotic drive. Cyrtodiopsis whitei males are not fertile until at least three weeks after eclosion and can survive for six months or more in the laboratory and field (Wilkinson \& Dodson, 1997). Consequently, a secondary aim of this study is to determine if expression of sex proportion and sperm development are influenced by age.

\section{Materials and methods}

\section{Laboratory stocks}

Flies used in this study were descended from animals captured with hand nets near Ulu Gombak, peninsular Malaysia (350 m elevation, $\left.3^{\circ} 19^{\prime} \mathrm{N}, 101^{\circ} 43^{\prime} \mathrm{E}\right)$ in January 1996. Subsequently, the laboratory population has been maintained with over 200 individuals in a plexiglass cage $(120 \times 36 \times 30 \mathrm{~cm})$. This cage was kept with others in an $8^{\prime} \times 10^{\prime}$ environmental chamber on a 12 -h light-dark cycle at $25 \pm 2{ }^{\circ} \mathrm{C}$ and at least $80 \%$ relative humidity. Pureed, autoclaved yellow maize treated with $10 \%$ methylparaben as a mould inhibitor was used for food and oviposition material (Wilkinson, 1993).

\section{Quantifying sex ratio and sperm development}

To determine if age or meiotic drive influence sperm development, we obtained progeny sex proportions and examined sperm development from males in cohorts which were allowed to reach $6,10,16,20$ or 26 weeks of age. After eclosion we housed males in groups of 20 in $1 \mathrm{~L}$ plastic jars $(12 \times 16 \times 13.5 \mathrm{~cm})$. Then, 3 weeks prior to attaining their target age, we placed single males with four 3-4 week-old virgin females in $1 \mathrm{~L}$ plastic jars to permit mating and egg laying. Twice a week we provided 
$40 \mathrm{~mL}$ of food in $100 \mathrm{~mL}$ cups for egg laying. After removal, cups containing eggs were placed on moist cotton inside $500 \mathrm{~mL}$ containers, plugged with foam stoppers, and kept at $25 \pm 1{ }^{\circ} \mathrm{C}$. Two weeks later food was discarded after transferring any remaining larvae or pupae to the cotton. Eclosed flies were sexed by genitalia inspection and counted. We collected egg cups from females for at least four weeks to insure adequate progeny were obtained to score a male's sex ratio phenotype.

Upon reaching target age, or in the event of death, mated males were removed from mating jars, immobilized by exposure to $-20^{\circ} \mathrm{C}$ for $5-10 \mathrm{~min}$, and dissected. Testes were removed, transferred to a clean glass slide, and their contents released into separate drops of PBS. Slides were then air-dried, fixed in a 3:1 solution of methanol:acetic acid, washed with PBS, and stained with Hoechst 33258 (Sakaluk \& O'Day, 1984) to identify DNA-containing regions. Slides were mounted in a mixture of elvanol (mowiol) and glycerol (Longin et al., 1993).

Using UV epifluorescence, we counted the total number of elongated spermatocyst bundles (Fig. 1) in each testis under 200× magnification using a Nikon E600 microscope. Cyst bundles were categorized as either long or short, corresponding to the two nonoverlapping size classes of sperm produced by this species (Presgraves et al., 1999). If at least five sperm

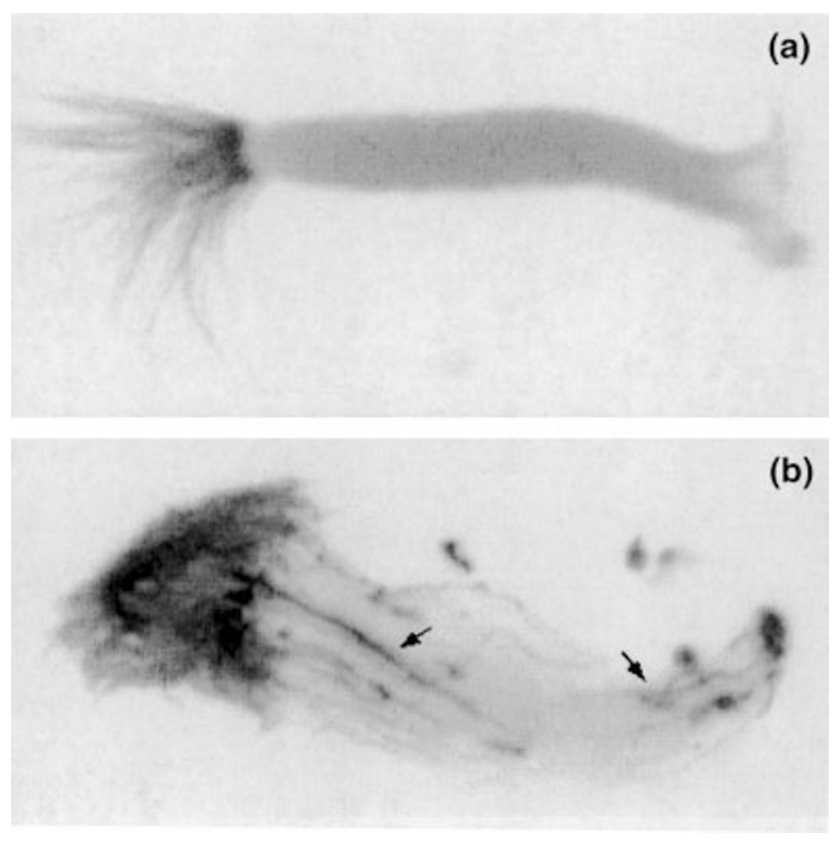

Fig. 1 Hoechst-stained elongated spermatocyst bundles from an (a) ST male and (b) SR male of Cyrtodiopsis whitei. Note spermatid nuclei and incompletely elongated spermatids in tail region of the spermatocyst bundle in (b). heads or cell nuclei could be observed in the tail region of the bundle, rather than at the tip (cf. MontchampMoreau \& Joly, 1997), cyst bundles were additionally categorized as containing nonelongated spermatids (see Fig. 1). In some cases elongated sperm heads appeared to contain beaded DNA that had not condensed properly or was degenerating (cf. Hauschteck-Jungen \& Maurer, 1976; Presgraves et al., 1997). Cyst bundles with this appearance were counted separately.

For each male, 10 spermatocyst bundles were also examined under $1000 \times$ magnification. Only spermatocysts beginning to differentiate into individual spermatids were chosen. For each of these bundles we counted the number of fluorescing cell nuclei or sperm heads which had failed to develop or elongate completely. Unfortunately, due to a mistake in stain preparation and subsequent lack of fluorescence, males in the 20 week category could not be scored for the presence of nonelongated spermatids. We were able, though, to count sperm bundles from these males using differential interference contrast illumination.

\section{Statistical analyses}

Offspring sex proportions were tested for deviation from 1:1 using chi-squared tests corrected for continuity. To minimize the effect of binomial sampling variance on progeny sex proportion, males producing less than 15 offspring were not included in analyses involving progeny sex proportion. Males producing a progeny sex proportion that differed significantly from 1:1, assuming $\alpha=0.01$, were designated as SR and males producing a progeny sex proportion not significantly different from 1:1 were designated as ST. One male produced a significantly male-biased sex proportion. Because we had no replication for this phenotype, we excluded this individual from all analyses involving sex ratio. No conclusions are affected by this exclusion.

Progeny counts are reported as offspring per cup to control for differences in male survival. We applied the angular transformation, i.e. arcsin-squareroot (proportion), to normalize proportions prior to parametric analysis. Descriptive statistics are provided as mean \pm 1 SE for untransformed variables.

\section{Results}

We scored sex ratio genotype from 66 males. Representation in each age group was nearly equal. Fourteen males were 6 weeks, 14 were 10 weeks, 17 were 16 weeks, 10 were 20 weeks and 11 were 26 weeks of age. Forty-five $(69 \%)$ of these males were categorized as SR and produced $16 \pm 2 \%$ male progeny. The remaining 21 ST males produced $47 \pm 1 \%$ male progeny. Analysis of 
covariance (ANCOVA) indicated that the proportion of male progeny differed significantly between SR and ST genotypes $\left(F_{1,63}=62.4, P<0.0001\right)$, but showed no effect of male age $\left(F_{1,63}=0.5, P=0.47\right)$ and no interaction. Thus, expression of male sex proportion appears to be independent of age.

On average, each male produced $175 \pm 12$ progeny from $7.5 \pm 0.4$ cups. ANCOVA on the average number of offspring produced per cup by each male revealed a significant effect of sex ratio genotype $\left(F_{1,63}=6.72\right.$, $P=0.012)$ but no effect of age $\left(F_{1,63}=2.20, P=0.14\right)$ and no interaction. SR males produced $73.5 \%$ as many offspring per cup as ST males, i.e. $22.2 \pm 1.4$ vs. $30.2 \pm 2.9$ flies per cup, respectively. Although age was not a significant covariate in this analysis, the oldest males produced more offspring than the youngest males, i.e. 6 week-old males produced $19.4 \pm 2.5$ offspring per cup whereas 26 week-old males produced $31.8 \pm 4.0$ offspring per cup.

Spermatocyst bundles were counted for 59 males, of which 54 were also scored for progeny sex proportion. A regression of the number of cyst bundles on age was significant $\left(F_{1,58}=8.4, P=0.0054\right)$ and showed that the number of spermatocyst bundles in male testes increased with age (Fig. 2). ANCOVA revealed that after removing the effect of age, the number of cyst bundles did not differ between SR and ST males $\left(F_{1,51}=0.03, P=0.87\right)$ and there was no interaction. ANCOVA also revealed no difference in the proportion of long morph spermato-

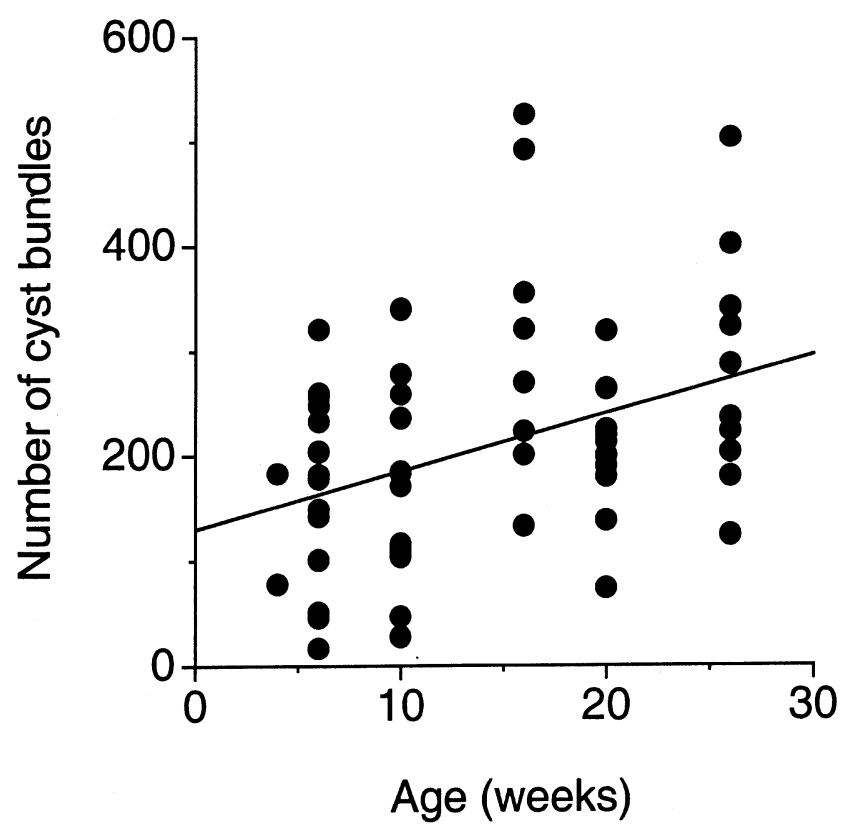

Fig. 2 Number of elongated spermatocyst bundles counted in both testes regressed against age for 61 Cyrtodiopsis whitei males. cysts between SR and ST males $\left(F_{1,51}=2.91, P=0.09\right)$ and no effect of age on the relative abundance of the two size classes of sperm $\left(F_{1,51}=1.03, P=0.32\right)$. The proportion of degenerate spermatocyst bundles also did not differ between sex ratio genotypes $\left(F_{1,51}=0.26, P=0.61\right)$ nor was affected by age $\left(F_{1,51}=0.24, P=0.62\right)$. On average, the proportion of spermatocyst bundles exhibiting a degenerate appearance was $0.069 \pm 0.010$.

In contrast to spermatocyst number, SR males did differ dramatically from ST males in having incompletely elongated sperm heads much more often in spermatocyst bundles (Fig. 3). ANCOVA on the proportion of cyst bundles with nonelongated spermatids revealed a highly significant effect of sex ratio genotype $\left(F_{1,42}=131.3, P<0.0001\right)$ but not of age $\left(F_{1,42}=1.88\right.$, $P=0.18)$. The average number of nonelongated spermatids in a sample of 10 spermatocysts also showed a highly significant effect of sex ratio $\left(F_{1,41}=14.84\right.$, $P=0.0004)$ with no effect of age $\left(F_{1,41}=2.3, P=0.14\right)$. SR males had up to 54 (average $10.7 \pm 1.3$ ) nonelongated sperm heads in each spermatocyst whereas ST males had, on average, only $3.0 \pm 1.1$ nonelongated sperm heads per bundle.

Categorization of males into two classes ignores variation in sex proportion within each category. To determine if expression of sex proportion can be predicted by sperm phenotype within and across sex ratio genotype, we regressed proportion of male offspring on each measure of sperm development. When

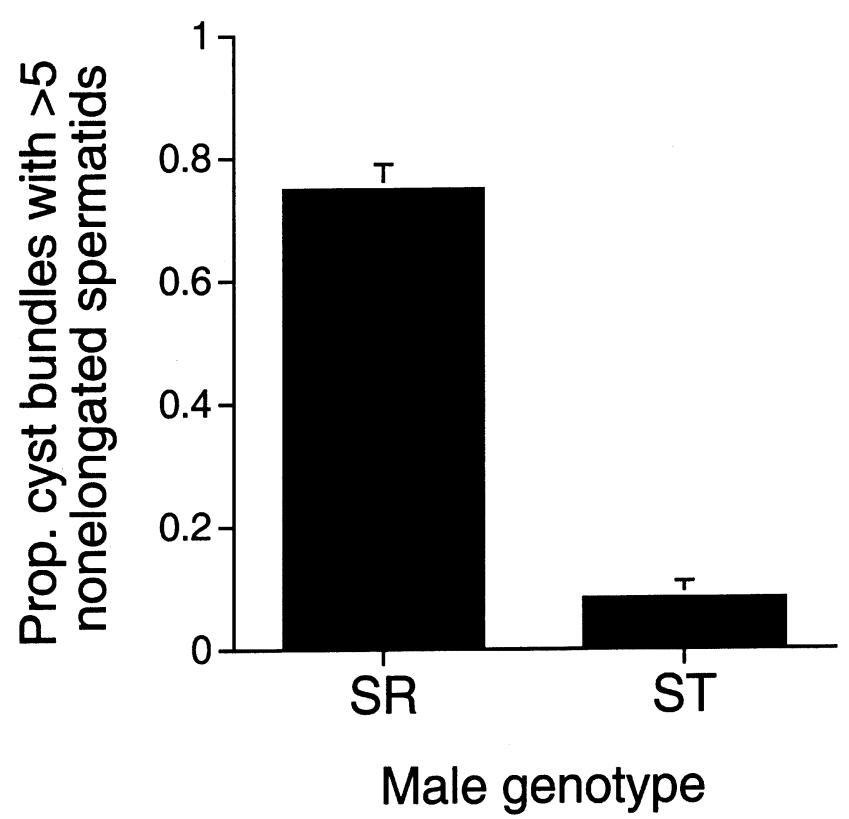

Fig. 3 Mean \pm SE of the proportion of elongated spermatocyst bundles of Cyrtodiopsis whitei with five or more spermatids in the tail region of a bundle (cf. Fig. 1).

(C) The Genetics Society of Great Britain, Heredity, 87, 17-24. 


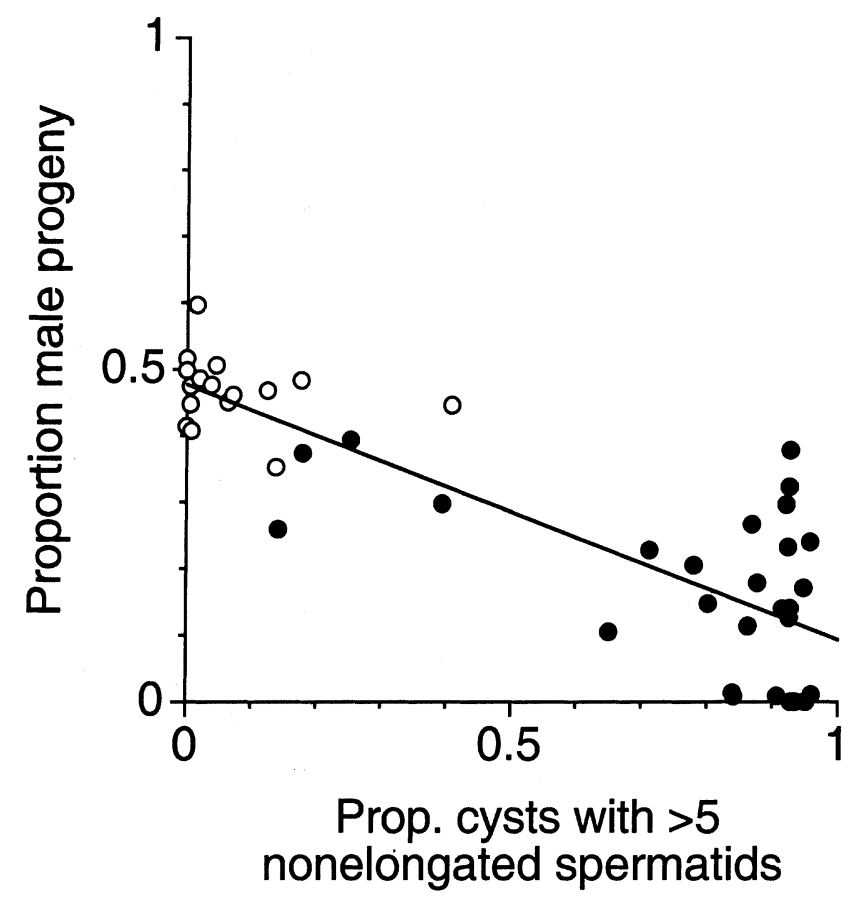

Fig. 4 Proportion of male progeny produced by 53 males of Cyrtodiopsis whitei plotted against the proportion of elongated spermatocyst bundles with five or more nonelongated spermatids in the tail region. Filled circles indicate SR males and open circles indicate ST males.

SR and ST male data are combined and both sperm phenotype measures are included in a multiple regression analysis, proportion of spermatocysts with nonelongated sperm significantly predicts progeny sex proportion $(t=5.6, P<0.0001)$ but number of nonelongated spermatids does not $(t=0.8, P=0.44)$. The proportion of spermatocysts with nonelongated sperm explained $71 \%$ of the variation in offspring sex proportion (Fig. 4). When each sex ratio genotype is analysed separately, proportion of spermatocysts with nonelongated sperm significantly predicted progeny sex proportion among SR males $(t=2.9, P=0.0081)$ but not among ST males $(t=0.9, P=0.37)$. In contrast, the number of nonelongated spermatids did not predict progeny sex proportion when SR and ST male data are analysed separately (SR: $t=1.9, P=0.067$; ST: $t=0.8$, $P=0.42$ ).

\section{Discussion}

The results reported here strongly suggest that sex chromosome meiotic drive alters the progeny sex proportion of male $C$. whitei because some sperm within a developing cyst bundle do not develop normally and are therefore incapable of fertilization. In contrast to reports for D. mediopunctata (Carvalho \& Klaczko, 1992) and D. melanogaster (Hiraizumi \& Watanabe, 1969), we found no effect of age on either the degree to which SR males produce female-biased progeny or the development of their sperm, although total sperm production did increase with age. Furthermore, in contrast to a previous study on $C$. dalmanni involving much fewer individuals (Presgraves et al., 1997), we found no difference between SR and ST males in the number of cyst bundles with a degenerate or beaded appearance. The presence of both normal and abnormal spermatids within a single spermatocyst bundle is consistent with the supposition that Y-bearing sperm are differentially affected. However, much less than half of the spermatids in a bundle exhibited abnormal development. Thus, not all Y-bearing spermatids failed to elongate. Given that the proportion of sperm bundles with nonelongated spermatids is a better predictor of progeny sex proportion than the average number of nonelongated spermatids per spermatocyst, we suspect that some Y-bearing spermatids which complete elongation are incapable of fertilization.

A critical review of the literature suggests that the cytological differences we observed between SR and ST male C. whitei closely resemble those found in Drosophila. Early work on D. pseudoobscura proposed that during the first meiotic division the $\mathrm{Y}$ chromosome undergoes nondisjunction whereas the $\mathrm{X}$ chromosome is duplicated and passed to all 128 spermatids (Sturtevant \& Dobzhansky, 1936). Later studies proved this interpretation to be incorrect. Novitski et al. (1965) showed that the $\mathrm{Y}$ typically undergoes nondisjunction during the second meiotic division and degenerates before being passed to the pole of the secondary spermatocytes. These authors indicated that all 128 spermatids in a bundle appeared normal. However, using electron microscopy Policansky \& Ellison (1970) showed that SR male $D$. pseudoobscura produce sperm bundles with about half as many mature sperm (55 instead of 112) as ST males.

These apparently contradictory results for D. pseudoobscura can be reconciled in light of work on two other sex ratio species. In D. subobscura, Hauschteck-Jungen \& Maurer (1976) found that in SR males spermatid nuclei were found much more frequently in the tail region of elongating sperm bundles than they were in control males. Seventy-eight percent of SR male sperm bundles contained 5-50 spermatids in the tail region in comparison with only $8 \%$ of control males. A very similar observation was recently reported for $D$. simulans SR males (Montchamp-Moreau \& Joly, 1997), with the exception that the spermatogonium in $D$. simulans undergoes four mitotic divisions prior to meiosis, thereby giving rise to 64 spermatids in a single bundle. 
Consequently, in $D$. simulans, SR males have between five and 28 (average 15) spermatids in the tail region (Montchamp-Moreau \& Joly, 1997). The presence of pairs of spermatids in the tail region containing either a $\mathrm{Y}$ chromosome or no sex chromosome indicates that nondisjunction of the $\mathrm{Y}$ chromosome must have occurred during the second meiotic division (Cazemajor et al., 2000). A previous report of autosomal sex ratio in D. simulans (Faulhaber, 1967) has been interpreted as a hidden X-linked drive system which is exposed by the presence of a polymorphism for a recessive autosomal suppressor (Hurst \& Pomiankowski, 1991). Autosomal suppressors of sex ratio in $D$. simulans are now known (Cazemajor et al., 1997). Montchamp-Moreau \& Joly (1997) suggest that two different sex ratio systems probably exist in $D$. simulans because Faulhaber (1967) described a dimorphism in sperm shape for sex ratio males which they did not observe. However, ultrastructure studies on Faulhaber's lines have revealed that D. simulans sex ratio males produce, on average, 33 normal spermatids per bundle, with variation between bundles ranging from 1 to 62 spermatids (Ramamurthy et al., 1980). Nonelongated spermatid nuclei showing degeneration and cytolysis were observed in bundles from sex ratio males (Ramamurthy et al., 1980). Thus, the apparent reduction in spermatid number reported previously for $D$. pseudoobscura (Policansky \& Ellison, 1970) is consistent with the cytological results from D. subobscura and D. simulans if one assumes that sperm bundle sections contained mature, elongated sperm just prior to individualization. At this stage, nonelongated spermatid nuclei would only be present in the tail of a bundle; therefore, sperm bundles of SR males would appear to contain fewer sperm than normal male bundles. The cytological findings for all three Drosophila are therefore remarkably consistent with our observations on the diopsid, C. whitei.

The primary difference between species appears to be the fraction of spermatids that fail to elongate and the concomitant effect that has on the production of males. In D. pseudoobscura half of the spermatids in a bundle are affected. In this species, males are rare in the progenies of SR/Y fathers. When they appear, they are X0 and sterile (Henahan \& Cobbs, 1983). In contrast, in $D$. simulans and D. subobscura, as well as in C. whitei, usually less than half of the spermatids are affected and some fertile males are produced (Hauschteck-Jungen \& Maurer, 1976; Ramamurthy et al., 1980). It is worth noting, however, that $30 \%$ of male progeny produced by D. simulans $\mathrm{SR}$ males are sterile and $\mathrm{X} 0$ males have been detected. We frequently observe male sterility in C. whitei (Lorch et al., 1993), but additional work is needed to determine if the sex chromosome complement of these sterile males is $\mathrm{X} 0$.
Another interesting parallel between sex chromosome meiotic drive in stalk-eyed flies and members of the obscura group in Drosophila is the presence of heteromorphic sperm. Bircher et al. (1995) proposed that heteromorphic sperm are required for the development and persistence of sex ratio in D. subobscura. They suggest that SR D. subobscura males do not have reduced fertility compared to ST males because SR males produce more small morph sperm than ST males. We find, in contrast, that the proportion of long morph sperm does not differ between SR and ST males. In addition, evidence to date shows that only long morph sperm penetrate and fertilize eggs in species of Drosophila with heteromorphic sperm, including D. subobscura (Snook \& Karr, 1998). Furthermore, given that sex chromosome meiotic drive is found in five other groups of Drosophila which lack heteromorphic sperm, we suspect that the occurrence of sperm heteromorphism and sex chromosome meiotic drive in stalkeyed flies, as well as in some obscura group Drosophila, is coincidental.

The reduced fertility we observed in SR C. whitei males suggests that they transfer fewer fertilizationcompetent sperm than ST males, as has been inferred for SR males in other species (Jaenike, 1996). In the absence of sperm competition, the relative fertility of SR males, as measured by the ratio of progeny produced per cup by SR vs. ST males, is not less than one-half and therefore is insufficient to stabilize a sex ratio polymorphism under frequency-dependent selection (Jaenike, 1996). However, female C. whitei remate frequently (Wilkinson et al., 1998a) and require at least five copulations to fill their spermathecae (Lorch et al., 1993). When female $C$. whitei mate multiple times on successive days, sperm mixing occurs and sperm precedence is usually shared equally (Lorch et al., 1993). Sperm competition and depletion studies involving SR and ST males are therefore needed to determine if frequency-dependent selection can stabilize the sex ratio polymorphism in these flies.

\section{Acknowledgements}

We thank John Swallow, John Jaenike and an anonymous reviewer for helpful comments on the manuscript. This work was supported by NSF grants DEB-9807937 and DEB-0077878.

\section{References}

BIRCHER, U., JUNGEN, H., BURCH, R. AND HAUSCHTECK-JUNGEN, E. 1995. Multiple morphs of sperm were required for the evolution of the sex ratio trait in Drosophila. J. Evol. Biol., 8, 575-588.

(C) The Genetics Society of Great Britain, Heredity, 87, 17-24. 
BUCKLER, D. S. T., PHELPS-DURR, T. L., BUCKLER, C. S., DAWE, R. K. ET AL. 1999. Meiotic drive of chromosomal knobs reshaped the maize genome. Genetics, 153, 415-426.

CARvalho, A. B. AND KlaczKo, L. B. 1992. Age and sex-ratio expression in Drosophila mediopunctata. Genetica, 87, 107-111.

CARVAlHO, A. B. AND KLACZKO, L. B. 1993. Autosomal suppressors of sex-ratio in Drosophila mediopunctata. Heredity, $\mathbf{7 1}$, 546-551.

CARVAlHO, A. B. AND KLACZKo, L. B. 1994. Y-linked suppressors of the sex-ratio trait in Drosophila mediopunctata. Heredity, 73, 573-579.

CARvalho, A. B. AND VAz, S. C. 1999. Are Drosophila SR chromosomes always balanced? Heredity, 83, 221-228.

CARVAlho, A. B., PEIXOTO, A. A. AND KlACZKO, L. B. 1989. Sex ratio in Drosophila mediopunctata. Heredity, 62 , 425-428.

CARVAlHo, A. B., VAZ, S. C. AND KLACZKo, L. B. 1997. Polymorphism for Y-linked suppressors of sex-ratio in two natural populations of Drosophila mediopunctata. Genetics, 146, 891-902.

CAZEMAJOR, M., LANDRE, C. AND MONTCHAMP-MOREAU, C. 1997. The sex-ratio trait in Drosophila simulans: genetic analysis of distortion and suppression. Genetics, 147, 635-642.

CAZEMAJOR, M., JOLY, D. AND MONTCHAMP-MOREAU, C. 2000. Sex-ratio meiotic drive in Drosophila simulans is related to equational nondisjunction of the Y chromosome. Genetics, 154, 229-236.

DERMITIZAKIS, E. T., MASLY, J. P., WALDRIP, H. M. AND CLARK, A. G. 2000. Non-mendelian segregation of sex chromosomes in heterospecific Drosophila males. Genetics, 154, 687-694.

EDWARDS, A. W. F. 1961. The population genetics of "sex-ratio" in Drosophila pseudoobscura. Heredity, 16, 291-304.

FAUlHABER, S. H. 1967. An abnormal sex-ratio in Drosophila simulans. Genetics, 56, 189-213.

GERSHENSON, S. 1928. A new sex-ratio abnormality in Drosophila obscura. Genetics, 13, 488-507.

GOODING, R. H. 1986. Evidence for genetic control of sex ratio distortion in two colonies of Glossina morsitans submorsitans Newstead (Diptera: Glossinidae). Quaest. Entomol., 22, $19-28$.

HAmilton, w. D. 1967. Extraordinary sex ratios. Science, 156, 477-488.

HAUSCHTECK-JUNGEN, E. AND MAURER, B. 1976. Sperm dysfunction in sex ratio males of Drosophila subobscura. Genetica, 46, 459-477.

HENAHAN, J. AND COBBS, G. 1983. Origin of X/O progeny from crosses of sex-ratio trait males of Drosophila pseudoobscura. J. Hered., 74, 145-148.

HIRAIZUMI, Y. AND WATANABE, S. 1969. Aging effect on the phenomenon of Segregation Distortion in Drosophila melanogaster. Genetics, 63, 121-131.

HURST, L. AND POMIANKOWSKI, A. 1991. Causes of sex ratio bias may account for unisexual sterility in hybrids: a new explanation of Haldane's rule and related phenomena. Genetics, 128, 841-858.

JAENIKe, J. 1996. Sex-ratio meiotic drive in the Drosophila quinaria group. Am. Nat., 148, 237-254.
JAENIKE, J. 1999a. 'Sex-ratio' meiotic drive and the maintenance of $\mathrm{Y}$ chromosome polymorphism in Drosophila. Evolution, 53, 164-174.

JAENIKE, J. 1999b. Suppression of sex-ratio meiotic drive and the maintenance of Y-chromosome polymorphism in Drosophila. Evolution, 53, 1326.

JAMES, A. C. AND JAENIKE, J. 1990. 'Sex ratio' meiotic drive in Drosophila testacea. Genetics, 126, 651-656.

LANDE, R. AND WILKINSON, G. S. 1999. Models of sex-ratio meiotic drive and sexual selection in stalk-eyed flies. Genet. Res., 74, 245-253.

LONGIN, A., SOUCHIER, C., FFRENCH, M. AND BRYON, P. 1993. Comparison of anti-fading agents used in fluorescence microscopy: image analysis and laser confocal microscopy study. J. Histochem. Cytochem., 41, 1833-1840.

LORCH, P., WILKINSON, G. S. AND REILlo, P. R. 1993. Copulation duration and sperm precedence in the Malaysian stalk-eyed fly, Cyrtodiopsis whitei (Diptera: Diopsidae). Behav. Ecol. Sociobiol., 32, 303-311.

LYTTLE, T. W. 1993. Cheaters sometimes prosper: distortion of mendelian segregation by meiotic drive. Trends Genet., 9, 205-208.

MERCOT, H., ATLAN, A., JACQUES, M. AND MONTCHAMP-MOREAU, C. 1995. Sex-ratio distortion in Drosophila simulans: co-occurrence of a meiotic drive and a suppressor of drive. J. Evol. Biol., 8, 283-300.

MERRILL, C., BAYRAKTAROGLU, L., KUSANO, A. AND GANETZKY, B. 1999. Truncated RanGAP encoded by the Segregation Distorter locus of Drosophila [see comments]. Science, 283, 1742-1745.

MONTCHAMP-MOREAU, C. AND JOLY, D. 1997. Abnormal spermiogenesis is associated with the X-linked sex-ratio trait in Drosophila simulans. Heredity, 79, 24-30.

MORI, L., DESSEN, E. M. B. AND PERONDINI, A. L. P. 1979. A gene that modifies the sex ratio in a bisexual strain of Sciara ocellaris. Heredity, 42, 353-357.

NOVITSKI, E., PEACOCK, W. J. AND ENGEL, J. 1965. Cytological basis of 'sex ratio' in Drosophila pseudoobscura. Science, $\mathbf{1 4 8 ,}$ 516-517.

PEACOCK, W. J., TOKUYASU, K. T. AND HARDY, R. W. 1972. Spermiogenesis and meiotic drive in Drosophila. In: Beatty, R. A. and Gluecksohn-Waelsch, S. (eds) Edinburgh Symposium on the Genetics of the Spermatozoon, pp. 247-268. Bogtrykkeriet Forum, Copenhagen.

POLICANSKY, D. AND ELLISON, J. 1970. 'Sex Ratio' in Drosophila pseudoobscura: spermiogenic failure. Science, 169, 888-889.

PRESGRAVES, D. C., BAKER, R. H. AND WILKINSON, G. S. 1999. Coevolution of sperm and female reproductive tract morphology in stalk-eyed flies. Proc. R. Soc. B, 266, 1041-1047. PRESGRAVES, D. C., SEVERENCE, E. AND WILKINSON, G. S. 1997. Sex chromosome meiotic drive in stalk-eyed flies. Genetics, 147, 1169-1180.

RAMAMURTHY, G., ALFERT, M. AND STERN, C. 1980. Ultrastructural studies on spermatogenesis in a sex-ratio mutant strain of Drosophila simulans. Am. J. Anat., 15, 205-219.

SAKALUK, S. K. AND O’DAY, D. H. 1984. Hoechst staining and quantification of sperm in the spermatophore and spermathecae of the decorated cricket, Gryllodes supplicans (Orthoptera: Gryllidae). Can. Entomol., 116, 1585-1589. 
SILVER, L. M. 1993. The peculiar journey of a selfish chromosome: mouse t haplotypes and meiotic drive. Trends Genet., 9, 250-254.

SNOOK, R. R. AND KARR, T. A. 1998. Only long sperm are fertilization-competent in six sperm-heteromorphic Drosophila species. Curr. Biol., 8, 291-294.

STALKER, H. D. 1961. The genetic systems modifying meiotic drive in Drosophila paramelanica. Genetics, 46, 177-202.

STURTEVANT, A. H. AND DOBZHANSKy, T. 1936. Geographical distribution and cytology of 'sex ratio' in Drosophila pseudoobscura and related species. Genetics, 21, 473-490.

wiLkinson, G. S. 1993. Artificial sexual selection alters allometry in the stalk-eyed fly Cyrtodiopsis dalmanni (Diptera: Diopsidae). Genet. Res., 62, 213-222.

WILKINSON, G. S. AND DODSON, G. 1997. Function and evolution of antlers and eye stalks in flies. In: Choe, J. and Crespi, B. (eds) The Evolution of Mating Systems in Insects and Arachnids, pp. 310-328. Cambridge University Press, Cambridge.

WILKINSON, G. S., KAHLER, H. AND BAKER, R. H. 1998a. Evolution of female mating preferences in stalk-eyed flies. Behav. Ecol., 9, 525-533.

WILKINSON, G. S., PRESGRAVES, D. C. AND CRYMES, L. 1998b. Male eye span in stalk-eyed flies indicates genetic quality by meiotic drive suppression. Nature, 391, 276-278.

WOOD, R. J. AND NEWTON, M. E. 1991. Sex-ratio distortion caused by meiotic drive in mosquitoes. Am. Nat., 137, 379391.

WU, C.-I. 1983. The fate of autosomal modifiers of the sex-ratio trait in Drosophila and other sex-linked meiotic drive systems. Theor. Pop. Biol., 24, 107-120. 